\begin{tabular}{|c|c|}
\hline & $\begin{array}{l}\text { International Journal of Trend in Scientific } \\
\text { Research and Development (IJTSRD) }\end{array}$ \\
\hline 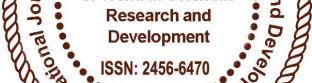 & International Open Access Journal \\
\hline 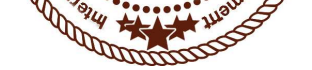 & ISSN No: 2456 - 6470 | www.ijtsrd.com | Volume - 2 | Issue - 2 \\
\hline
\end{tabular}

\title{
Experimental Study on Heat Transfer and Fluid Flow Characteristcs of Shell and Tube Heat Exchanger using hiTRAN Wire Inserts
}

\author{
Manoj Shendre \\ Assistant Professor, Department of \\ Mechanical Engineering, Guru Nanak \\ Dev Engineering College, Bidar, India
}

\author{
Sandeep Biradar \\ Assistant Professor, Department of \\ Automobile Engineering, Guru Nanak Dev \\ Engineering College, Bidar, India
}

\section{ABSTRACT}

Heating and cooling process of fluid streams is - a standard operation in petrochemical and other industries. This operation is often performed in heat exchangers where the hot or cold fluid flows inside and outside the tubes. Shell and tube heat exchangers are most widely used in practical applications. They are also having special importance in process industries as well as in refrigeration and air conditioning industries. The analysis of heat exchanger performance is difficult, since it involves both forced and natural convection heat transfer due to the complex mechanisms conditions are considered. Heat transfer in case of laminar flow (Re $<2000$ ) regimes is normally low but can be enhanced by the use of tube inserts or tabulators.

In present paper, the heat transfer and fluid flow characteristics of heat exchanger (Shell and tube) are determined experimentally by using of hiTRAN wire matrix inserts for laminar flow conditions. hiTRAN wire matrix tube inserts effectively disturbs the fluid flow in tube side due to the hydrodynamic disturbance of boundary layer in the heat exchanger. These results in increase in the wall shear stress, reduced wall temperature and hence enhance substantial increase in tube side heat transfer rate. The effect of mass flow rate of water on heat transfer characteristics is also investigated in case of plain tube without inserts. An experimental study of heat transfer characteristics with and without inserts has been carried out using water -water system on 1-2 pass shell and tube heat exchanger. Heat transfer characteristics like heat transfer coefficient, pressure drop and friction factor are calculated for shell and tube heat exchanger with and without insert. It is observed that there is improvement in the performance of heat exchanger by using hiTRAN wire matrix inserts. The heat transfer coefficient found to be increased from $300 \%$ to $350 \%$ with hiTRAN wire matrix inserts when compared with that of a heat exchanger without inserts. The friction factor found to be increased from $350 \%$ to $380 \%$, pressure drop increased from $320 \%$ to $350 \%$ and Coburn ' $\mathrm{j}$ ' increased from $160 \%$ to $200 \%$ respectively when compared with Heat exchanger without inserts.

Keywords: Shell and tube exchanger, hiTRAN inserts, heat transfer coefficient, pressure drop, friction factor

The mechanism of laminar heat transfer in horizontal tube is complex as they can be forced, natural and mixed convection. The dominant mechanism depends on the condition and physical properties of the fluid being heated or cooled [1] (Holmen 1992). The fluid is forced through the tube at low enough velocities the natural convection buoyancy force still have effect on flow pattern inside the tube. Metais and Exkert (1964) [2] have proposed the forced mixed and free convection regimes in horizontal tube. Nusselt number correction by Sieder and Tate (1936) and Oilver (1962) for laminar, forced and mixed 
convection are used to compare the result from with various heat transfer parameter in case hiTRAN tube insert Chandrasker et al (2010-2011) conducted the experiments which involve usage of a wire coil insert fitted in circular tube which showed that there was rise in heat transfer rate with insignificant rise in friction factor in plain tube and tube with wire coil inserts. Saqr and Musa (2009) investigated the consequence of repetitive fin discontinuity on convective heat transfer coefficient for pipes with internal longitudinal fins and found that smaller the discontinuity off set distance higher is heat transfer coefficient. Thome (1997) investigated that the proper usage of tubular heat transfer enhancement techniques will be able to minimize the linier dimensions of tube of heat exchanger about 25 to $75 \%$ when checked with plain empty tube heat exchanger. Hosseini et al (2007) experimentally studied the heat transfer and pressure drop characteristics of shell and tube heat exchanger by providing various external tube surfaces. The main reason that the shell and tube heat exchangers are generally being employed in energy and chemical industries are due to their moderately simple manufacturing is involved and their flexible in nature of installation to the different operating condition. Manufacturing and operating cost of any heat exchangers are impacted by internally depended parameters for example heat transfer rate, heat transfer coefficient and pressure drop. The modern types of inserts are used on tube side to improve the turbulence so has to enhance the heat transfer coefficient and effectiveness of heat exchanger. The present scenario of increased effect on climatic condition more efficient heat transfer equipments are mandatory for automotive and production industries with heat exchanger compact in size with optimizing heat transfer techniques. The usage of different tabulators on tube side results in improved heat transfer characteristics which reduces the equipment size. The main purpose of this work is to study the enhancement in heat transfer characteristics and its effect on pressure drop using wire matrix inserts under the laminar flow condition in shell and tube heat exchanger.

\subsection{Introduction to hiTRAN wire matrix inserts:}

Sometimes the problem to be solved is simple-poor thermal performance. Although the heat exchanger designer always aim for high heat transfer coefficient this can sometimes be difficult to achieve with a conventional plain tube design. In many cases this due to the properties of tube side fluid such as high viscosity and low thermal conductivity. Occasionally low heat transfer rates are a consequence of the arrangement of the exchanger such as when single pass tube bundles are require. Whatever the reason, poor tube side performance can usually be avoided by considering the use of heat transfer enhancement technologies. Engineering devices such as hiTRAN matrix elements in variably provides increased heat transfer relative to the plain tube. When fluid flow through the plain tube the fluid nearest to the wall is subjected to the frictional drag which has the effect of slowing down the fluid at the wall this laminar boundary layer can significantly reduce the tube side heat transfer coefficient and consequently the performance of heat exchanger. Inserting correctly the profiled hiTRAN wire matrix element into the tube will disrupt the laminar boundary layer, creating the additional fluid shear and mixing, her by minimizing the effect of frictional drag. hiTRAN wire matrix tabulators are particularly effective at enhancing heat transfer efficiency in tubes operating at low Reynolds number (Laminar to transitional flow). Although heat transfer increase is greatest in the laminar flow region (up to 16 times) significant benefits can be obtained in the transitional flow regime (up to 12 times) and turbulent regime (up to 3 times). Whilst there is an increase in frictional resistance associated with hiTRAN system, the amount of enhancement such that solution can be found which offer increased heat transfer at equivalent or low pressure drop than a plain tube.

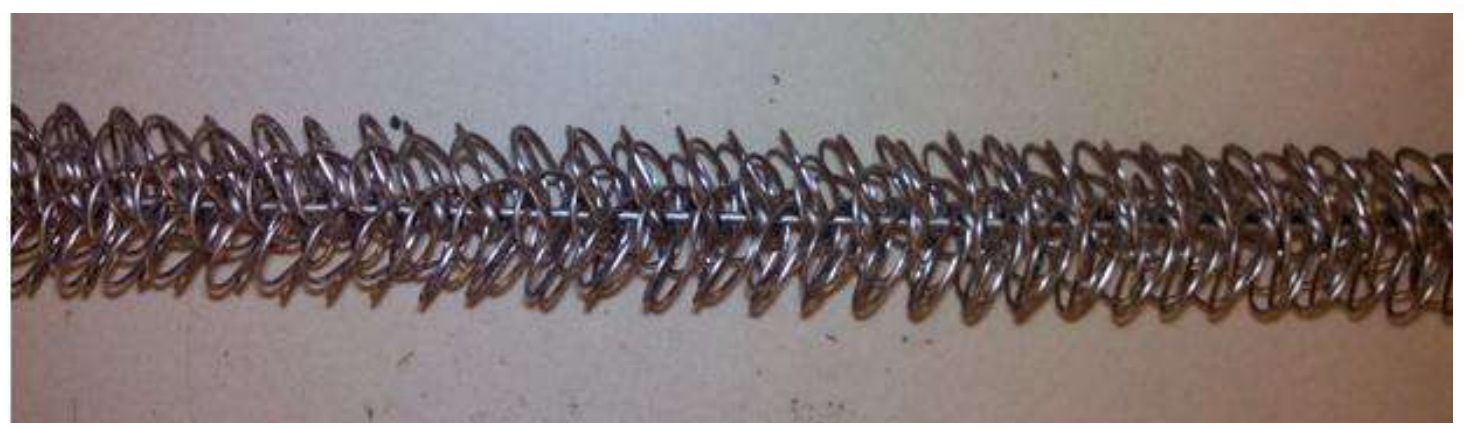

Fig.1 High density hiTRAN inserts. 


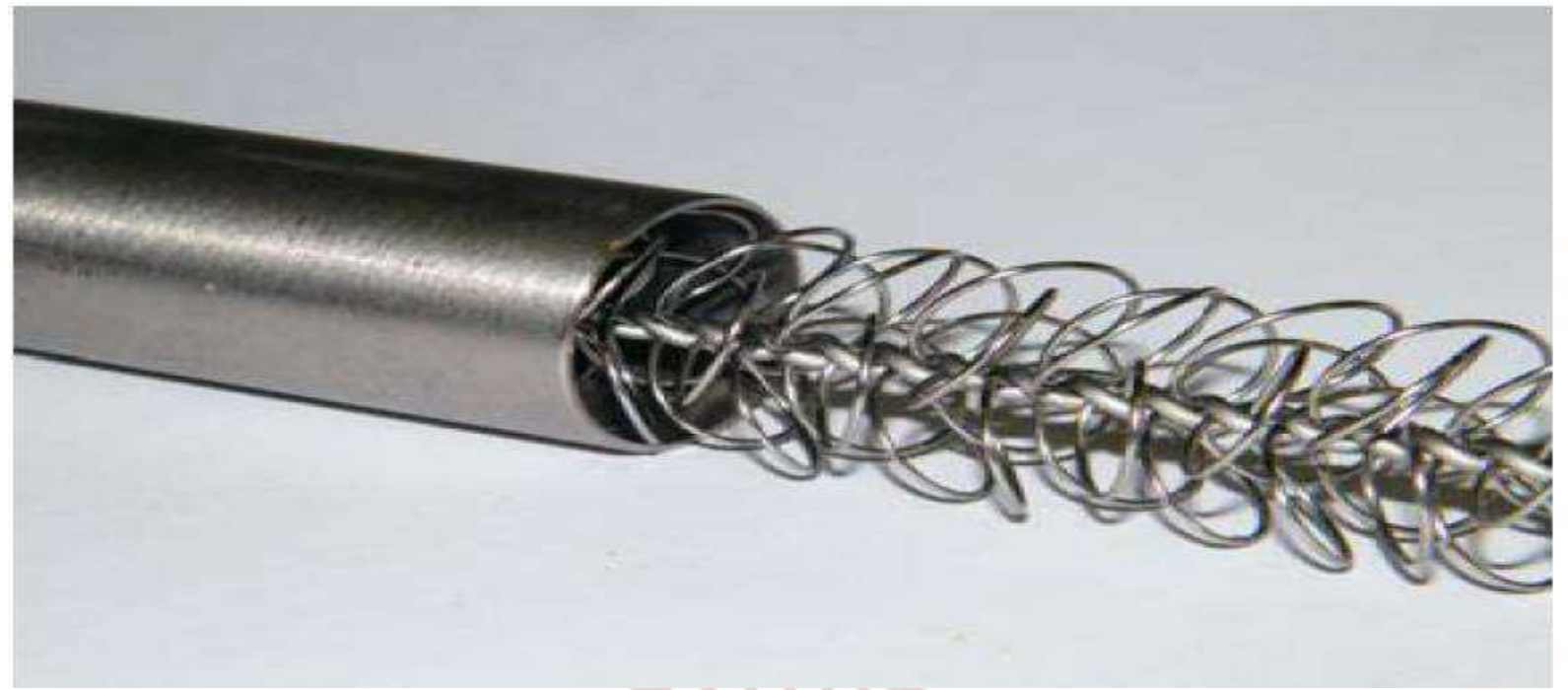

Fig.2 Low density hiTRAN inserts

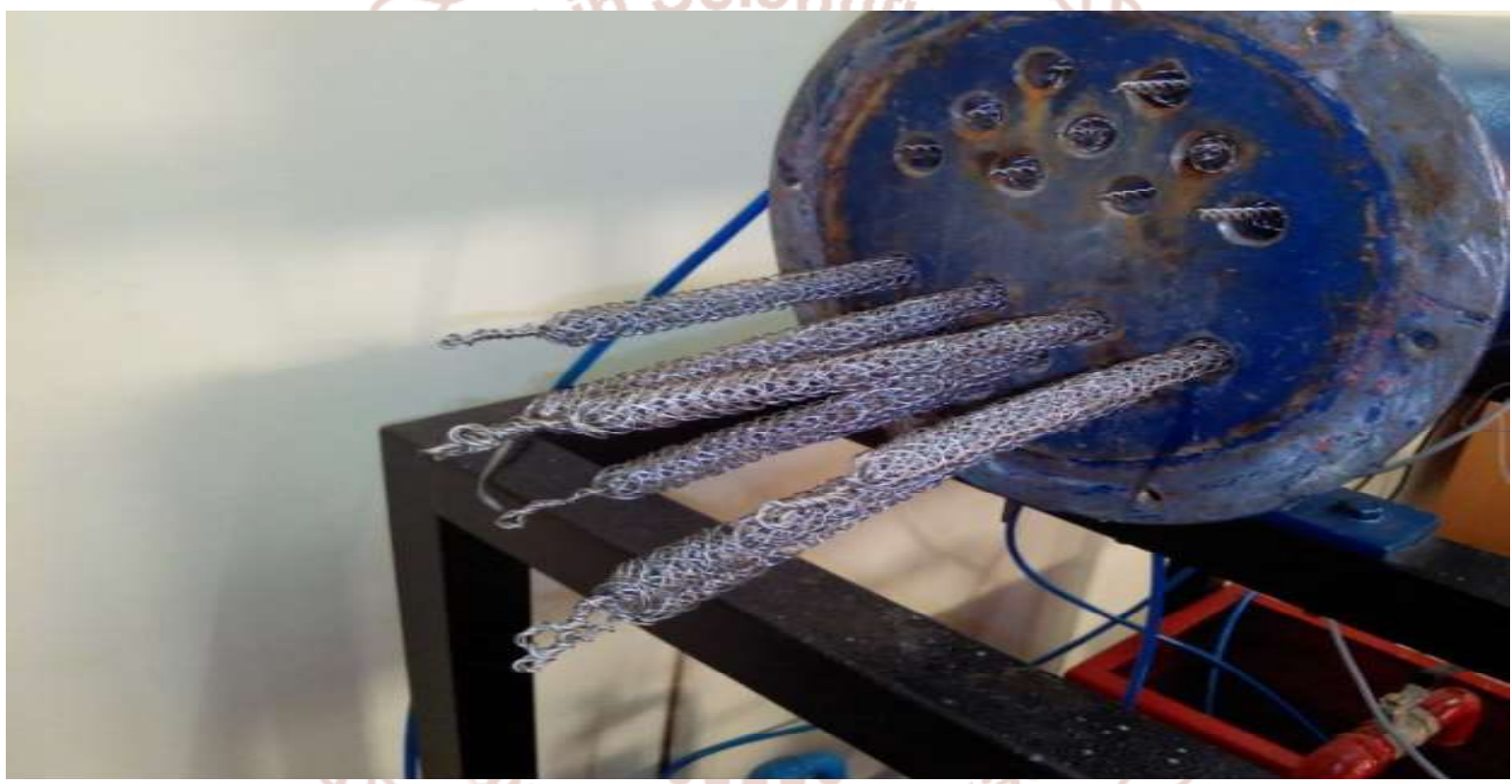

Fig.3 Tubes inserted with hiTRAN turbulators

\section{WORKING PRINCIPLE OF HITRAN:}

hiTRAN wire matrix elements work by constantly mixing fluids from the tube wall into the main bulk flow and vice versa. hiTRAN disturbs the laminar flow layers, characteristics for these flow Reynolds number, resulting in significantly higher heat transfer coefficient on the tube side wall which in turn helps to reduce the risk of fouling. Fig.4 Dye stream injection at Reynolds number 500 in $16 \mathrm{~mm}$ diameter tube. The above image display hiTRAN working by using dye as an experiment. Using hiTRAN in the above example dye was injected into the flow at the top and the bottom of glass tube wall. In situations where the does not have a dye insert position, the dye steam remained on the tube side wall for the entire length as shown on the above up stream image at point A. On hitting first loop within the hiTRAN example the dye stream is fitted from the wall and gradually pushes into bulk flow which is also shown above at point B. It is clear from the above image that under laminar and transitional flow condition the residence time near the wall is reduced heavily compared to the plain empty tube case in order to quantify the effect fouling applications, the resulting flow behavior and heat transfer when using hiTRAN elements. In this set up, dye is injected into the flow at the centre and the bottom of the glass tube wall. In areas without an insert present and Re below 5000, dye stream remained on tube wall for the entire length. On reaching the first loop however, the dye stream is lifted from the wall and dispersed into the bulk flow. 
For Re below 2300 there is no convective mixing between fluid layers therefore hiTRAN shows the highest improvements in terms of heat transfer in the Re range from about 100 to 2300 . But it is also evident that for transitional and even turbulent flow heat transfer enhancement can be achieved. Under laminar and transitional flow conditions it is clear that the fluid residence time near to the wall is much reduced compared to the plain empty tube case. This can be beneficial to suppress certain types of heat exchanger fouling. An additional effect is the increased wall shear when applying hiTRAN.

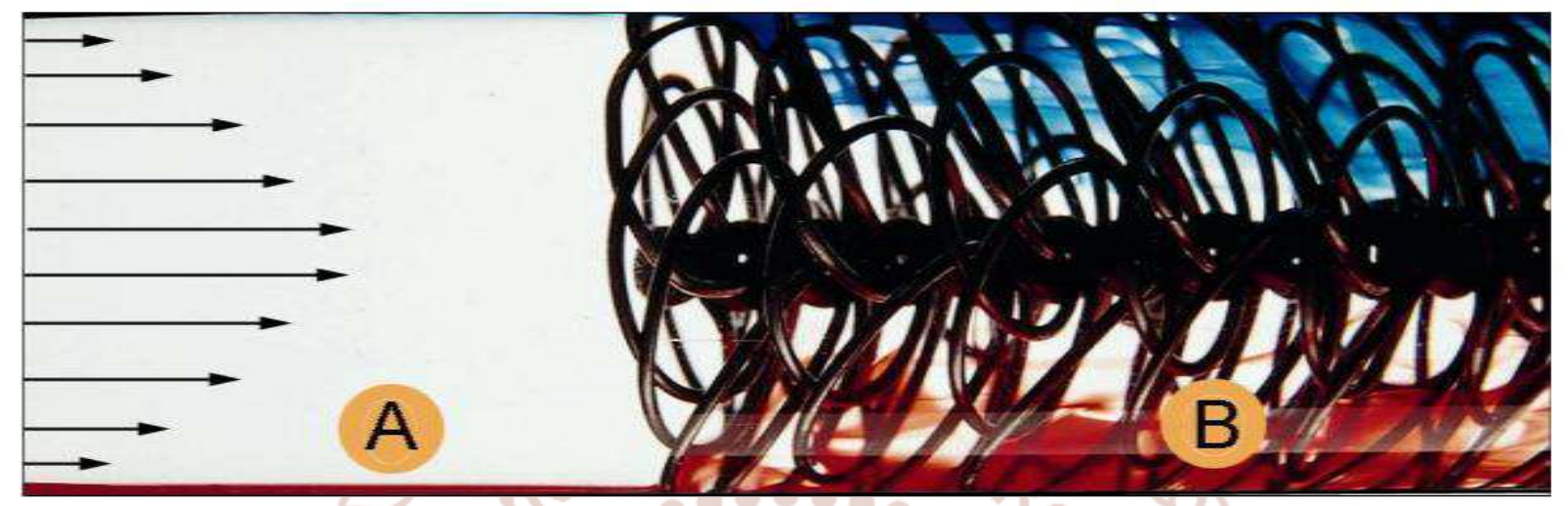

Fig.4 Dye stream injection at Reynolds number 500 in $16 \mathrm{~mm}$ diameter tube.

\section{EXPERIMENTAL SET UP:}

Schematically representation heat exchanger experimental set up used to investigate the heat transfer enhancement of water to water type shell and tube heat exchanger is shown in figure. Single shell multiple tube two pass heat exchangers is used for experiment the hot water is supplied in tube side via flow meter using hydraulic pump, similarly cold water on shell side. Heat exchanger of shell and tube type is being utilized in this experiment consisting of shell with ID 0.2 meter and of tubes with ID and OD are 0.016 meter and 0.1924 meter respectively. There are about 16 numbers of tubes made up of stain less steel are used each of which has length 0.825 meter with the pitch of 0.03 meter. The heat exchanger is provided with equally spaced four numbers of baffles with baffle cut $35 \%$ is adopted. In order to reduce the amount of heat loss to surrounding the shell and pipe lines where insulated. The hiTRAN wire matrix inserts are used which is made out of stainless steel is being inserted in each tube. 


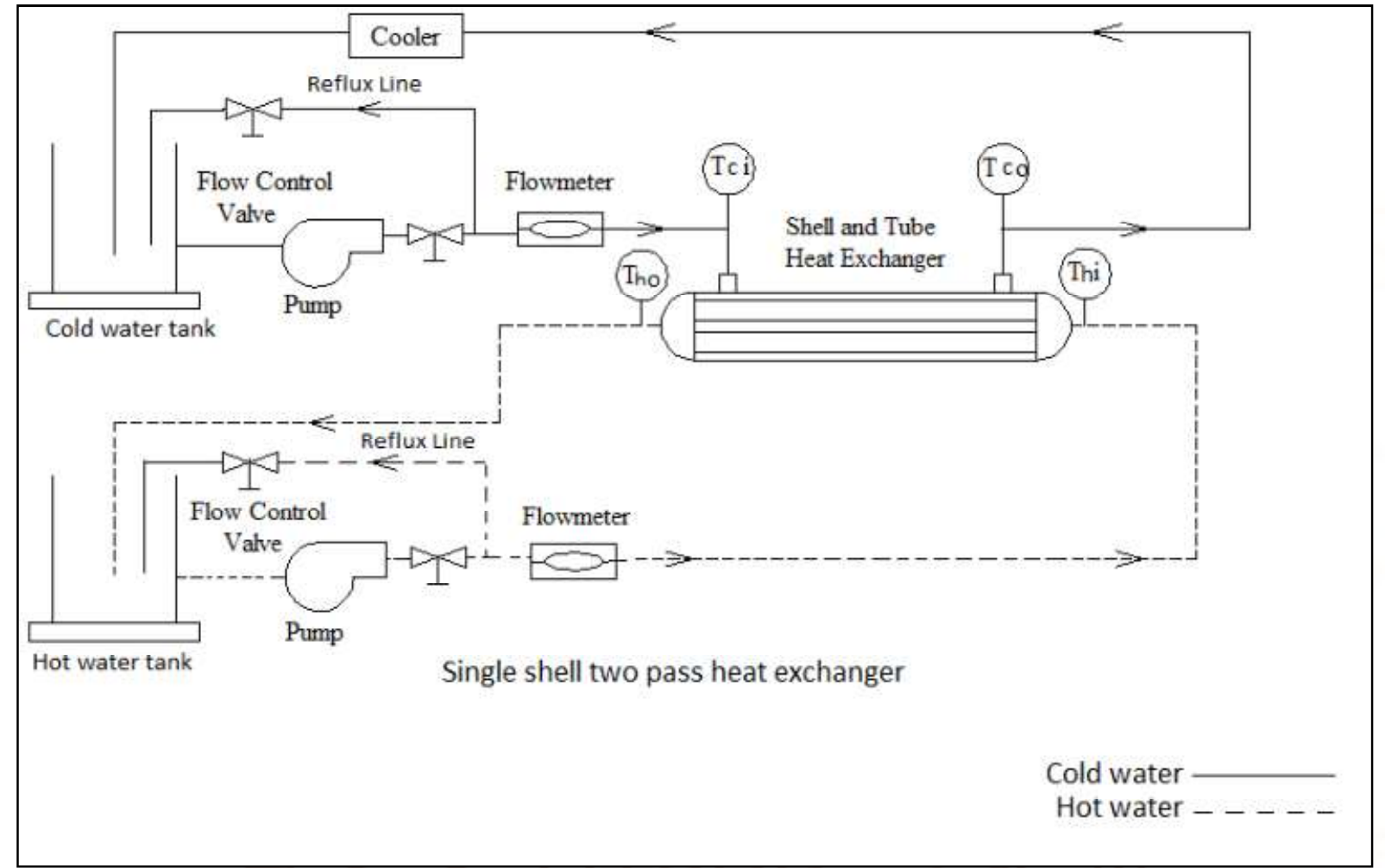

Fig.5 Line diagram of Single shell two pass heat exchanger.

\section{EXPERIMENTAL APPARATUS:}

Two stainless steel tanks with a capacity 30 litters each were taken for the purpose of holding water. One tank is assembled with electrical water heater so that water can be heated. Two centrifugal pumps were used in the experiment one for hot water and other for cold water. With the aim of maintaining the volume flow rate a bypass line with a control valve is used in both the loops. Four thermocouple of standalone Ktype with range of 0 to $1200 \mathrm{c}$ and $0.10 \mathrm{c}$ accuracy where inserted into the inlet and out let of the shell and tube heat exchanger. The thermocouples measures $T_{h i}, T_{\text {ho }}$ temperatures of hot water at inlet and exit point of tube side similarly other two thermocouples measures $\mathrm{T}_{\mathrm{ci}}, \mathrm{T}_{\mathrm{co}}$ temperatures of cold fluid at inlet and exit point respectively on shell side.

\section{EXPERIMENTAL PROCEDURE:}

After the proper cleaning of entire experimental set up, the distilled water was filled in both of the tanks. Water in one tank is heated by means of electrical water heater to a stipulated temperature. When water is attained a particular temperature the pump is switched on and water is made to flow through the tube via controlling bypass valve. Simultaneously the cold water is circulated through the shell side after attaining the steady state condition, temperature, pressure and flow rates are measured the volume flow rate was varied by controlling valve and corresponding values noted down. In the next attempt the tubes are inserted with hiTRAN wire matrix turbulator and the above procedure was repeated and corresponding readings are noted down. The graphs different natures of graphs were plotted against various parameters and plots were being compared for plain empty tube and tubes with hiTRAN inserts. 


\section{RESULT AND DISCUSSION:}

\subsection{Heat transfer coefficient v/s Reynolds number.}

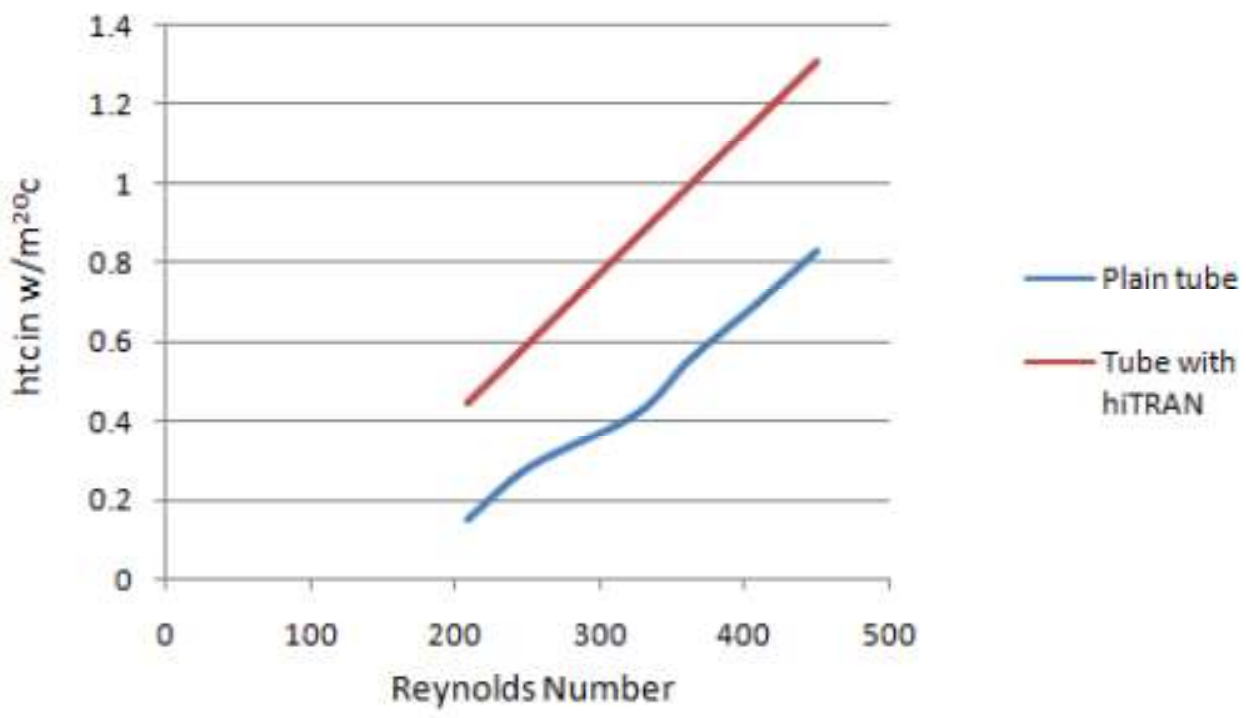

The above plot synthesizes the variation of heat transfer coefficient with respect to variation in Reynolds number. It resembles the increase in heat transfer coefficient in presence of hiTRAN wire matrix inserts compared to that of plain empty tube. It is observed that in case of laminar flow for the Reynolds number from 220 to 550 the boundary layer which forms between the bulk flow and tube surface, decreases the flow of heat from wall to the fluid which increases the wall temperature. With the aid of wire matrix inserts there is disturbance in boundary layer due to increase in shear in fluid flow. This result in increase in heat transfer coefficient both by means of nature as well as forced convection. The heat transfer coefficient is increased by $120 \%$ to $130 \%$ in presence on hiTRAN compared to that of the plain empty tube.

\subsection{Pressure drop v/s Reynolds number.}

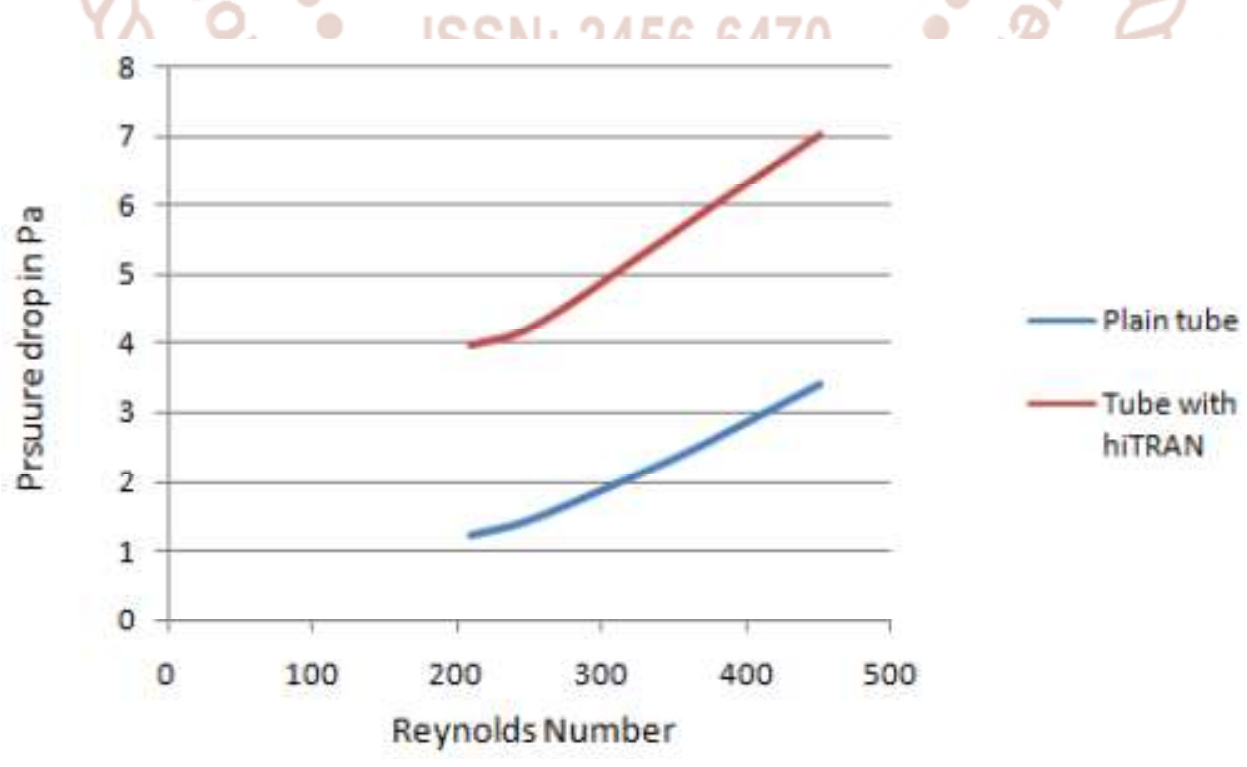




\subsection{Nusselt Number v/s Reynolds number.}

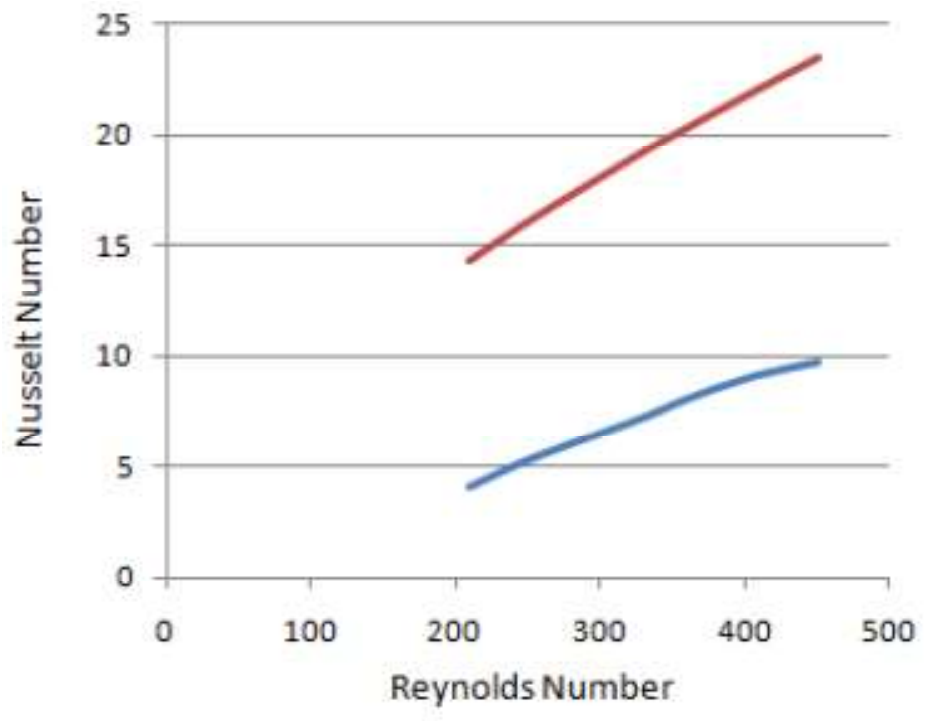

- Plain tube

Tube with hITRAN

\subsection{Friction factor v/s Reynolds numbers}

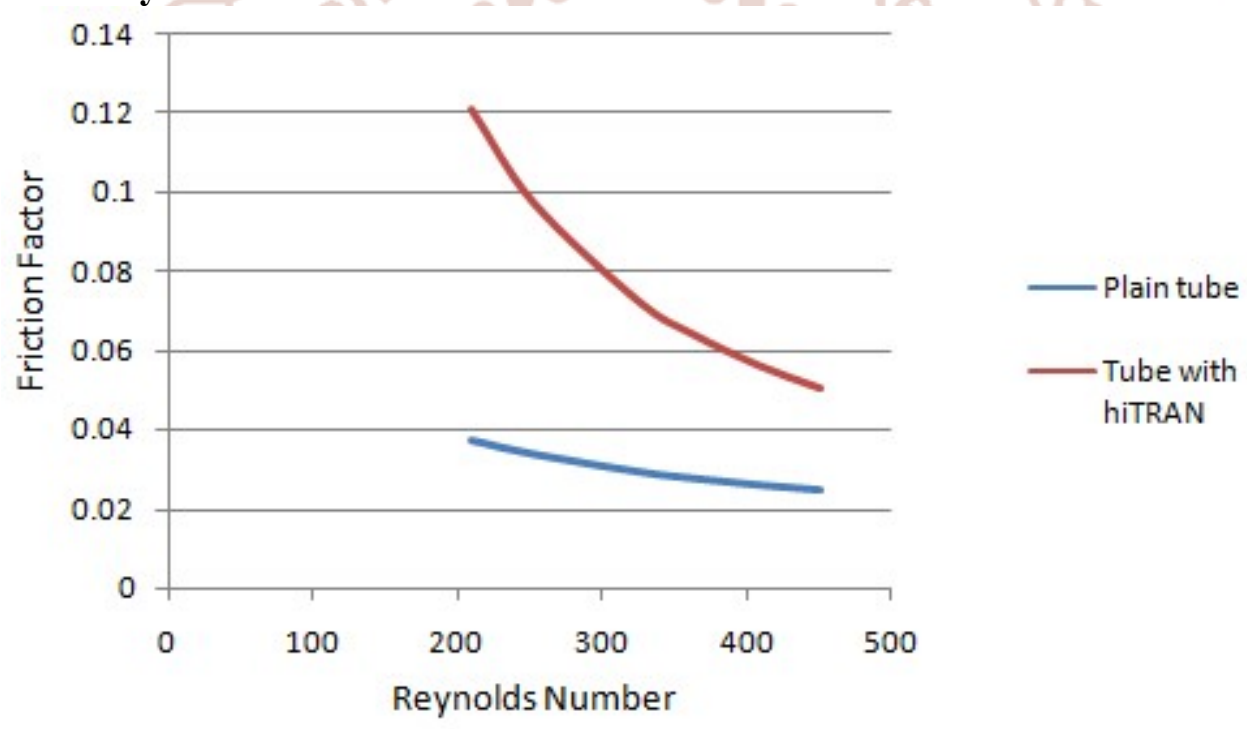

The friction factor results were compared to the plain empty tube and tube with the hiTRAN wire matrix inserts. The plain empty tube analysis indicates an increase in friction factor to the adiabatic case due to the fact that near to the wall a more viscous layer is found. Overall results show that hiTRAN inserts increases the friction factor above that of an empty tube. The greatest increase is seen with the hiTRAN wire matrix inserts with $400 \%$ increase. However the increase in friction factor is balanced by having an increase in tube side heat transfer coefficient.

\section{CONCLUSION:}

This paper discusses the possibility of altering the plain empty tube conditions concerning to the heat transfer coefficient, rate of heat transfer and pressure drop by using hiTRAN tube inserts. It has been observed from the experiments that there is drastically increase in heat transfer rate in case of tube loaded with hiTRAN inserts for same flow rate of fluid. The hiTRAN is effectively used to increase the turbulence of tube side flow. The main applications are in transitional and laminar flow regimes, but hiTRAN element is also used in turbulent flow in case were additional pressure drop is available in the system. At a time when meeting the competing requirements of lowest size, cost, reduced energy using all the means available to achieve these aims is vital. The enhancement of tube side heat transfer coefficient through hiTRAN wire matrix element is shown to be one of these means for applicable services. Having become established in providing such enhancement in laminar or transitional liquid flow regimes that list of 
applicable services now been extended to include certain two phase applications.

\section{REFERENCES}

1. Holman J.P, 1992. Heat transfer, 7th edition, Mc Graw Hill, Newyork, USA.

2. Meta B and Eckert E R G, 1964, Forced, Mixed and Free Convection Regimes, Journal Of Heat Transfer 86. 295

3. Sieder E.N, Tate G.E, 1936, Heat Transfer and Pressure Drop In Tubes, Industrial and Engineering Chemistry, 289(12), 1429-1435.

4. Oliver D.R, 1962, The Effect Of Natural Convection On Viscous Flow Heat Transfer In Horizontal Tubes, chemical engineering science $17,5,335-350$.

5. Chandrasekar, M., Suresh, S. and Chandrabose, A. 2010. Experimental Studies on Heat Transfer and Friction Factor Characteristics of Al2O3/water nanofluid in a circular pipe under laminar flow with wire coil inserts, Experimental Thermal Fluid Science 34: 122-130.
6. Chandrasekar, M., Suresh, S. and Chandrabose, A. 2011. Experimental Studies on Heat Transfer and Friction Factor Characteristics of A12O3/water nanofluid in a circular pipe under transition flow with wire coil inserts, Heat Transfer Engineering, 32 (6): 485-496.

7. Saqr, K.M. and Musa, M.N. 2009. Numerical study of the heat transfer augmentation in pipes with internal discontinues longitudinal fins, International journal of Mechanical and Materials Engineering 4 (1): 62-69.

8. Thome, J.R. 1997. Heat transfer augmentation of shell-and-tube heat exchangers for the chemical processing industry, Journal of Enhanced Heat Transfer 4 (2): 147-161.

9. Hosseini, R., Hosseini-Ghaffar, A. and Soltani, M. 2007. Experimental determination of shell side heat transfer coefficient and pressure drop for an oil cooler shell-and-tube heat exchanger with three different tube bundles, Applied Thermal Engineering 27: 1001-1008. 